\title{
Direito à SAÚde do TRABalhador
}

\author{
WORKER'S RIGHT TO HEALTH
}

Otavio Pinto e Silva*

A Revista de Direito Sanitário traz no presente número um importante tema para debate: a saúde do trabalhador.

Trata-se de uma excelente oportunidade para que a comunidade acadêmica possa refletir sobre as normas jurídicas (previstas tanto na Constituição quanto na legislação infraconstitucional) que denotam não somente a preocupação com a ausência de doenças, mas também com a busca do completo bem-estar físico, mental e social do indivíduo em sua comunidade.

Nessa perspectiva, Janete Lima de Castro analisa a prestação de serviços na área de saúde, na busca de estratégias de gestão que possam envolver os profissionais na construção de processos e territórios saudáveis de trabalho.

Márcia Cunha Teixeira discute se no atual contexto de crescimento econômico brasileiro os agravos à saúde dos trabalhadores são visíveis e se o respeito às normas protecionistas é praticado e incentivado pelas empresas e pelo Estado.

Já Roseli Schminski Vieira, Reginaldo de Souza Vieira, Ivanir Prá Silva Thomé e Ismael Francisco de Souza abordam a atuação dos enfermeiros nas notificações compulsórias de trabalho precoce, com base na experiência das unidades de estratégia de Saúde da Família do município de Criciúma/SC.

Como se vê, são artigos que examinam diferentes problemas, mas que giram em torno de um núcleo conceitual unitário que é a tutela da vida e da saúde.

Na observação de José Maria Sánchez Bursón ${ }^{(1)}$, é possível coordenar as diferentes respostas normativas do Estado para ações que visam à tutela

(*) Professor doutor, Faculdade de Direito, Universidade de São Paulo. Advogado. São Paulo/SP - Brasil. E-mail: otavio@siqueiracastro.com.br.

Texto recebido em 08.05.2012.

(1) SÁNCHEZ BURSON, José Maria. Aproximación a un concepto de derecho sanitario: noción y sus fuentes. Revista de Trabajo, Madri, n. 94, p. 45-72, 1989. 
da saúde dos cidadãos, compondo um conjunto heterogêneo, mas sem que os componentes singulares percam cada qual sua natureza.

Dentre essas várias áreas de atuação estatal podem-se incluir, então, aquelas que estão relacionadas à proteção da vida e da saúde do trabalhador em face dos riscos que podem ser encontrados no meio ambiente de trabalho.

Importante lembrar que a Constituição do Brasil estabelece que todos têm direito ao meio ambiente ecologicamente equilibrado, bem de uso comum do povo e essencial à sadia qualidade de vida, impondo-se ao Poder Público e à coletividade o dever de defendê-lo e preservá-lo para as presentes e futuras gerações (Art. 225). E quando se refere às atribuições do sistema único de saúde, o texto constitucional deixa claro que a ideia de meio ambiente do trabalho está compreendida na proteção do meio ambiente (Art. 200, inciso VIII).

Além disso, a Constituição ainda prevê no Art. $7^{\circ}$, inciso XXII, o direito dos trabalhadores urbanos e rurais à redução dos riscos inerentes ao trabalho, por meio de normas de saúde, higiene e segurança, o que justifica a necessidade de uma contundente ação do Poder Público na defesa do meio ambiente de trabalho.

Em consonância com essas diretrizes fundamentais, o Brasil ratificou a Convenção $n^{\circ} 155$ da Organização Internacional do Trabalho (OIT), (2) que prevê o dever dos Estados de formular, pôr em prática e reexaminar periodicamente uma "política nacional" coerente em matéria de segurança e saúde dos trabalhadores e o meio ambiente de trabalho, com o objetivo de prevenir os acidentes e os danos à saúde que forem consequência do trabalho ou que tenham relação com o trabalho, ou se apresentarem durante o trabalho, reduzindo ao mínimo, na medida em que for razoável e possível, as causas dos riscos inerentes ao meio ambiente de trabalho.

Essa "política nacional" deve levar em conta cinco grandes esferas de ação:

a) os componentes materiais do trabalho (locais de trabalho; ferramentas, maquinário, equipamentos; substâncias e agentes químicos, biológicos e físicos; operações e processos);

b) as relações existentes entre os componentes materiais do trabalho e as pessoas que o executam ou supervisionam;

c) o treinamento das pessoas envolvidas com a obtenção dos níveis adequados de higiene e segurança;

d) a comunicação e a cooperação entre as pessoas envolvidas;

e) a proteção dos trabalhadores e de seus representantes contra medidas disciplinares em face de sua atuação na busca dos objetivos de redução dos riscos inerentes ao trabalho.

(2) Aprovada pelo Decreto-Legislativo $\mathrm{n}^{\circ} 2$, de 17 de março de 1992, e promulgada pelo Decreto $\mathrm{n}^{\circ}$ 1.254 , de 29 de setembro de 1994. 
No Capítulo V do Título II da Consolidação das Leis do Trabalho(3) (CLT) estão elencadas as disposições que traçam a ação do Poder Público no que se refere à tutela da vida e da saúde do trabalhador, de modo que cabe ao Ministério do Trabalho e Emprego as funções precípuas de regulamentação das normas gerais de medicina e segurança do trabalho e de fiscalização do seu cumprimento.

Renato Bignami lembra que a eficácia dos serviços de inspeção pressupõe sistemas sancionatórios apropriados em caso de infrações, mas observa que "a correta dosagem entre punição e prevenção é que garantirá o avanço da Inspeção do Trabalho no Brasil como instituição legitimada pelos atores sociais a fim de garantir a aplicação do ordenamento jurídico trabalhista"(4).

Nessa direção, muito importante e oportuna a previsão inserida no artigo 627-A da CLT, que facultou a instauração de procedimento especial para ação fiscal com o objetivo de orientar as empresas sobre o cumprimento das leis de proteção ao trabalho, bem como prevenir e sanear eventuais infrações mediante a celebração de termo de compromisso.

É preciso lembrar também a disposição contida no Art. 154 da CLT, no sentido de que a observância, em todos os locais de trabalho, das regras previstas na legislação trabalhista não desobriga as empresas do cumprimento de outras disposições que estejam incluídas em códigos de obras ou regulamentos sanitários dos estados ou municípios em que se situem os respectivos estabelecimentos. Isso bem demonstra o aspecto multidisciplinar dessa legislação.

Os empregadores devem cumprir e fazer cumprir as normas de medicina e segurança do trabalho, instruir os empregados quanto às precauções a tomar no sentido de evitar acidentes de trabalho ou doenças ocupacionais, adotar as medidas que Ihe sejam determinadas pelas Superintendências Regionais do Trabalho e Emprego e facilitar a fiscalização.

Os empregados devem observar as normas de medicina e segurança do trabalho, inclusive instruções repassadas pelo empregador, e colaborar com a empresa na aplicação dos dispositivos legais. Nesse sentido, constitui ato faltoso do empregado (punível até mesmo com o rompimento do contrato de trabalho: despedida por justa causa), a recusa injustificada à observância das instruções expedidas pelo empregador ou ao uso dos equipamentos de proteção individual fornecidos pela empresa.

O Ministério do Trabalho e Emprego, por meio de portarias, aprova as chamadas Normas Regulamentadoras (NRs), de fundamental importância para dar concretude àquela "política nacional" propugnada pela OIT.

(3) Consolidação das Leis do Trabalho. Disponível em: <http://www.planalto.gov.br/ccivil_03/ Decreto-Lei/Del5452.htm>.

(4) BIGNAMI, Renato. A inspeção do trabalho no Brasil. São Paulo: LTR, 2007. p. 177. 
Em meio à essa intensa atividade regulamentar podem ser destacadas as matérias que envolvem:

a) órgãos internos das empresas, como os Serviços Especializados em Engenharia de Segurança e Medicina do Trabalho (Sesmet, conforme previsão da NR-4) e a Comissão Interna de Prevenção de Acidentes (CIPA, conforme previsão da NR-5);

b) programas ambientais e sanitários, como o Programa de Controle Médico de Saúde Ocupacional (PCMSO, conforme a NR-7), o Programa de Prevenção de Riscos Ambientais (PPRA, conforme a NR-9);

c) classificação das atividades e operações como perigosas (conforme NR-16, quando por sua natureza ou métodos de trabalho, impliquem o contato permanente com inflamáveis ou explosivos em condições de risco acentuado) ou insalubres (conforme NR-15, quando por sua natureza, condições ou métodos de trabalho, exponham os empregados a agentes nocivos à saúde, acima dos limites de tolerância fixados em razão da natureza e da intensidade do agente e do tempo de exposição aos seus efeitos);

d) Condições Sanitárias e de Conforto no Local de Trabalho (conforme a NR-24, que fixa regras sobre as instalações sanitárias, vestiários, refeitórios, cozinhas, alojamentos, condições de higiene e conforto por ocasião das refeições, fornecimento de água potável) e Ergonomia (conforme a NR-17, que estabelece parâmetros que permitam a adaptação das condições de trabalho às características psicofisiológicas dos trabalhadores, de modo a proporcionar um máximo de conforto, segurança e desempenho eficiente).

Em conclusão, pode-se afirmar a importância da existência de normas jurídicas trabalhistas que sejam efetivas e eficazes, e que representem a preocupação do Estado em garantir a saúde, a vida e a integridade física do trabalhador no meio ambiente de trabalho.

Como bem acentua Amauri Mascaro Nascimento, "os aspectos puramente técnicos e econômicos da produção de bens não poderiam redundar num total desprezo às condições mínimas necessárias para que o homem desenvolvesse a sua atividade conforme condições humanas e cercadas das garantias destinadas à preservação de sua personalidade"(5).

Cabe ao direito fixar os parâmetros a serem observados pelos empregadores, ficando para o Estado a difícil e relevante tarefa de exigir o cumprimento dessas normas, com o objetivo de proteger a vida e a saúde dos trabalhadores e assim fazer valer, na prática, o princípio constitucional da dignidade da pessoa humana.

(5) NASCIMENTO, Amauri Mascaro. Curso de direito do trabalho. São Paulo: Saraiva, 2009. p. 527 


\section{REFERÊNCIAS}

BIGNAMI, Renato. A inspeção do trabalho no Brasil. São Paulo: LTR, 2007. NASCIMENTO, Amauri Mascaro. Curso de direito do trabalho. São Paulo: Saraiva, 2009.

SÁNCHEZ BURSON, José Maria. Aproximación a un concepto de derecho sanitario: noción y sus fuentes. Revista de Trabajo, Madri, n. 94, p. 45-72, 1989. 